\title{
El papel de la filosofía con respecto a las relaciones entre fe y ciencia
}

(The role of philosophy regarding the relationship between faith and science)

\author{
JUAN ARANA \\ Universidad de Sevilla \\ jarana@us.es
}

Resumen. Hay las diversas disciplinas que emplean la razón como un elemento esencial de su trabajo. La ciencia positiva, la filosofía y la teología son probablemente las tres más relevantes. Dado el protagonismo que la ciencia ha tenido y tiene en nuestra cultura, es muy importante que entre ella y la teología se entable un diálogo constructivo. Por desgracia, no se han recogido en este campo los frutos que era legítimo esperar, en gran parte porque la filosofía no ha asumido como hubiera sido deseable el papel de mediadora que le correspondía. En este trabajo se examinan las causas históricas de este fenómeno y se proponen algunas vías para ayudar a resolverlo

Palabras clave: ciencia; teología; filosofía; diálogo constructivo.

Abstract. There are different disciplines that make use of reason as an essential element of its work. The most relevant are probably positive science, philosophy and theology. Opening a constructive dialogue between science and theology is very important because of the relevance that science has had in our culture. Unfortunately, the legitimately expected results in this field have not been achieved, mostly because the philosophy 
has not assumed the pertinent intermediary role as it was expected. In this article, the historic causes of this fact are analyzed and some ways to help to resolve it are proposed.

Keywords: science; theology; philosophy; constructive dialogue.

En su carta apostólica La puerta de la fe, el papa Benedicto XVI comenta los desafíos que ha de superar la fe cristiana en este ya bien entrado siglo XXI. Hace una referencia a la Fides et ratio de su predecesor Juan Pablo II para glosar los retos que plantea la racionalidad científica:

En efecto, la fe está sometida más que en el pasado a una serie de interrogantes que provienen de un cambio de mentalidad que, sobre todo hoy, reduce el ámbito de las certezas racionales al de los logros científicos y tecnológicos. Pero la Iglesia nunca ha tenido miedo de mostrar cómo entre la fe y la verdadera ciencia no puede haber conflicto alguno, porque ambas, aunque por caminos distintos, tienden a la verdad (Benedicto XVI 2011, n. 12) (Juan Pablo II 1998, nn. 31-32, 86-87).

El texto es muy sugerente y está preñado de resonancias. Una de ellas es que fe y razón son como dos ramas que nacen de un mismo tronco. Sin embargo, las vicisitudes de la historia las han separado tanto que muchos incluso las consideran extrañas y hasta enfrentadas. El hombre de fe no puede aceptar que este alejamiento se haga definitivo. Y si además ejercita la razón por profesión y vocación, es imperativo que intente atajar el proceso de mutuo extrañamiento para recuperar la armonía que en un principio hubo y siempre debió haberse mantenido.

En cierto modo la situación que vivimos es paralela a la que conoció la figura cuya fiesta celebramos. En la época de Tomás de Aquino se aceptaba que la razón por antonomasia se encontraba en la filosofía aristotélica. Sería legítimo decir que también entonces el ámbito de las certezas racionales "se había reducido" a lo que aquel admirado filósofo sostenía. Los más autorizados intérpretes, desde Alejandro de Afrodisias pasando por Averroes y desembocando en los primeros representantes del averroísmo latino, sostenían la incompatibilidad de la razón así "reducida” y la fe tal como la enseñaba la Iglesia. La misión histórica del gran dominico fue 
resolver el pretendido conflicto, mostrando que era posible aproximar de nuevo dos hermanas antes separadas.

También ahora echamos de menos la presencia de un nuevo Tomás de Aquino. Si la filosofía de Aristóteles fue lo mejor que dio de sí la racionalidad antigua, la ciencia y la tecnología representan el más importante logro de la racionalidad moderna. Así como los escoliastas estrecharon en un momento dado el caudal de lo razonable hasta identificarlo con una raquítica versión del aristotelismo que era incompatible con las verdades de la fe, el cientificismo ha hecho lo mismo con lo que desde el Renacimiento se ha averiguado acerca de la realidad con el apoyo de las matemáticas y la experiencia. En este contexto se puede repetir lo que Jesucristo comentó a propósito de las prácticas de divorcio que usaban los judíos, cuando les recriminó la dureza de sus corazones: "al principio no fue así” (Mateo, 19:8).

Si el Tomás de Aquino del siglo XIII mostró que sólo la cerrazón mental de los coetáneos podría declarar incompatibles la razón aristotélica y la fe cristiana, hoy necesitamos un nuevo santo que haga lo mismo con la fe cristiana y la ciencia moderna. Pero, como ya señaló un clásico de la espiritualidad del siglo XX, la presente crisis, como todas, es una crisis de santos. En todas las épocas los hay, pero no siempre tan grandes como para llevar a cabo las tareas de gigantes que aguardan cumplimiento. A la espera de que surja, podemos al menos señalar por dónde habría que avanzar y alegrarnos con ciertos signos evidentes de que - aunque sea poco a poco y entre muchos- algo se va haciendo.

Como es obvio, las analogías entre la situación pasada y la presente tienen límites, pero no hay que desdeñarlas. Una cosa que Tomás vio con singular lucidez es que no se trataba de "bautizar" a Aristóteles, coronando con una superestructura confesional un edificio conceptual susceptible de ser rematado de cualquier otro modo. Él percibía entre ambas instancias un parentesco íntimo. En lugar de puntos de tangencia buscaba raíces comunes. Por eso se aplicó a indagar en los más profundos estratos de aquella filosofía, y se atrevió incluso a completarla con perspectivas que su autor no había detectado, pero que constituían su culminación natural, casi una exigencia teórica de completitud y coherencia. Eso le permitió rectificar el 
dudoso concepto de Dios que aparece en el estagirita, reforzar su apertura a la trascendencia, aligerarlo de adherencias cósmicas, desbrozar incluso la senda que conduce del de Deo uno al de Deo trino. Me atrevo incluso a especular que si Aristóteles levantara de nuevo la cabeza y conociese la Suma teológica, diría sin dudarlo: este es el Dios que no vana pero sí insuficientemente busqué toda mi vida con la razón.

Si pasamos a la presente coyuntura, diría que mostrar la compatibilidad de la ciencia y la fe es muy poco. Las desvaídas tesis conciliaristas no dan frío ni calor, es como el desangelado encuentro de dos antiguos enemigos a los que el cansancio y los años han mellado la dentadura y apaciguado el odio. Se puede y debe trabajar por un objetivo más ambicioso, sobre todo si nos tomamos la molestia de conocer la entraña íntima del supuesto adversario.

La coexistencia pacífica no es el estado más deseable para las relaciones entre ciencia y fe. Corresponde a una situación de armisticio, un cese provisional de hostilidades entre facciones que no han resuelto su conflicto. Un alto el fuego casi siempre es promovido por la parte más débil, la que se bate a la defensiva y pide cuartel para recobrar resuello y preparar la contraofensiva. Durante más de un siglo fue la táctica preferida -y, dicho entre paréntesis, erróneamente seguida- por muchos apologistas de la religión, que, ayunos de argumentos, preferían edificar una especie de muralla china alrededor del amenazado reducto. Un síntoma de que las cosas están empezando a cambiar para bien es que últimamente también la usan los enemigos de la religión. Uno de los casos más llamativos es el de Stephen Jay Gould, que publicó en 1999 el libro Ciencia versus religión. Un falso conflicto. Formulaba así lo esencial de su propuesta:

Propongo que encapsulemos este principio básico de la no interferencia respetuosa (acompañado de un diálogo intenso entre los dos temas distintos, cada uno de los cuales cubre una faceta fundamental de la existencia humana) enunciando el principio de los magisterios que no se superponen (Gould 2000, 13).

Inmediatamente después dejaba claro que su posición ante la religión era agnóstica y demostraba a cuán poca profundidad había enterrado el hacha de guerra: 
Pero no puedo pensar en una afirmación más extraña a las normas de la ciencia (en realidad, más poco ética bajo este magisterio) que la célebre reconvención que Jesús hizo a Tomás: “dichosos los que sin ver creyeron”. Una actitud escéptica hacia las apelaciones basadas sólo en la autoridad, combinada con una exigencia de evidencia directa (en especial cuando se trata de apoyar afirmaciones insólitas), representa el primer mandamiento de la actitud científica correcta (Gould 2000, 13, 22).

Este texto demuestra con qué facilidad un buen científico se convierte a veces en un mal filósofo, ya que, si fe es creer en lo que no vimos, pocos hacen un ejercicio más reiterado y dispendioso de la fe que los científicos. En efecto: constantemente se fían de la verdad de lo que la naturaleza muestra con las inciertas evidencias empíricas, de lo que sus instrumentos revelan por vías siempre indirectas, o de lo que otros científicos y testigos afirman sin que sea posible comprobar al cien por cien la verdad de tales testimonios. El hombre de ciencia presta fe a todas esas instancias problemáticas porque está convencido de que la verdad anhelada existe y porque se sabe capaz de enderezar su camino hacia ella en medio de dudas, rodeos y vacilaciones. Exactamente lo mismo pasa con el hombre que busca a Dios empleando los auxilios que le brinda la razón. Sin embargo, cuando el éxito corona los esfuerzos del científico, no es raro que se olvide de la modestia de los medios empleados y de los riesgos de la aventura que ha vivido, para pretender con miope altanería que no hay conocimiento más seguro e inequívoco que el suyo. Cuando los generales victoriosos paseaban su triunfo por las calles de Roma, un siervo colocado tras a ellos les repetía: "Recuerda que eres mortal”. Bien podría ser esta una primera contribución positiva de la filosofía al diálogo ciencia-fe: recordar tanto a los científicos como a los teólogos que sus trabajos conjugan a la vez lo divino y lo humano, lo más soberbio y lo más humilde. Unos se ocupan de Dios y otros de la Creación, que es la sublime obra de sus manos. Pero para llevar a término su trabajo sólo cuentan con una razón bien limitada y un medio de expresión, el lenguaje, que se deshace en las manos como blanda roca pulverizable. El error común tanto de los científicos de ahora como de los teólogos cuando sucumbieron a la tentación de la soberbia 
intelectual, fue y es confundir la grandeza objetiva de la verdad investigada con el resultado de sus afanes, olvidando la pequeñez de los medios a su disposición para acercarse a ella.

Jesús increpó amorosamente a sus discípulos asustados por el fragor de una tormenta en el mar de Galilea. Bastantes apologistas se amedrentaron de modo parecido ante la ofensiva de una ciencia que parecía expropiar a Dios el gobierno del universo para entregarlo al ciego azar o una necesidad anónima. De ahí la pretensión de encerrar el saber acerca del mundo en una jaula de trivialidad sin provecho ni perjuicio para la religión. Del modo más pusilánime temían que el estudio de los efectos llegara a desmentir el saber acerca de las causas. Veían en la mecánica de Laplace o en la evolución de Darwin un manantial de argumentos antiteológicos, convirtiéndose así en cómplices involuntarios de los más endebles intérpretes del mensaje de la ciencia. Una vez más adolecían no de un exceso de mala filosofía como sus adversarios, sino de un déficit de sana filosofía, lo cual les impedía situar en su justo contexto los admirables descubrimientos de la mecánica celeste o la biología.

¿Y de qué se asustan ahora los herederos y continuadores del materialismo científico, a los que una mirada superficial otorgaría la victoria más completa en la cultura contemporánea? Por una parte, el agusanamiento interno de la cultura dominante ya es de por sí un síntoma revelador de que está asentada sobre una falsa fe. Por otra, desde hace algunos decenios las luces de alarma empiezan a encenderse una tras otra en el tablero de control del pensamiento naturalista. Los resultados de las investigaciones positivas desautorizan sin paliativos la camisa de fuerza filosófica que les ha sido impuesta. Vestir de inmanencia lo que cuentan las ciencias requiere hoy en día un esfuerzo sometido a la ley de rendimientos decrecientes: cada vez es más arduo imprimir a nuestros descubrimientos un giro hacia la inmanencia. Así se ha dado el caso de que las mismas murallas que antaño fueron erigidas para defender la religión, hoy se emplean como bastión de la increencia.

Podría parecer oportunismo impugnar la validez de refugios donde no hace mucho solían buscar amparo los espíritus piadosos. Por fortuna, 
el ejemplo de Tomás de Aquino sirve para convencernos de que antes de que se ensayaran esas inhábiles maniobras defensivas hubo quien siguió tácticas mejores. En efecto: con gran presencia de ánimo planteó Tomás la discusión en el terreno favorito del adversario: la razón desnuda de auxilios sobrenaturales, aunque no por ello desprovista del sostén de la gracia, en cuanto que también es don otorgado por el Todopoderoso. Seguía en esto la indicación de Santiago cuando afirmó que "todo lo bueno y perfecto que se nos da, viene de arriba, de Dios, que creó los astros del cielo" (Santiago, 1:17). Puesto que todo lo valioso proviene de una misma fuente, es impensable que haya conflictos o divergencias entre lo que de ella procede. La unidad del conocimiento es corolario de la unidad de los principios últimos de la realidad. La teoría de la doble verdad sólo podría corresponder a un mundo desajustado consigo mismo, producto de deidades en pugna un poco al estilo de lo que enseñaban los maniqueos. Aunque haya diferencias formales entre el conocimiento proporcionado por la fe y el que otorga la razón, ambos se refieren a la misma realidad, y por tanto no pueden desembocar en tesis contrapuestas. Para ser más exactos habría que matizar que la razón propiamente dicha no es una facultad de conocimiento autónoma, puesto que siempre bebe en manantiales que la trascienden. Depende siempre de una fe: fe en lo que los hombres dicen, en lo que los sentidos muestran, en lo que las pruebas indican. La fe religiosa depende ciertamente de una gracia que está más allá de las fuerzas de la naturaleza humana, pero, desde que se le negó a Pedro su petición de edificar tres tiendas y permanecer para siempre en la cima de la montaña, la misión del hombre de fe es bajar otra vez al valle y fecundar allí con la nueva semilla todas sus facultades y esfuerzos, de manera que para él tampoco es ajeno nada de lo humano, y la razón se convierte en un momento necesariamente asociado al despliegue y culminación de la vocación religiosa.

Así resulta comprensible por qué el aristotelismo cristiano nunca cuestionó en sus períodos de esplendor la integración orgánica de saberes que había diseñado el filósofo griego: física, matemática y teología natural constituyeron siempre para los grandes escolásticos las partes sustantivas de la filosofía, a las que la lógica agregaba un complemento propedéutico. 
Hay quien pretende que esta concepción unitaria del saber pertenece a la parte periclitada de la filosofía aristotélica, y que el nuevo saber introducido por Copérnico, Galileo y Newton es de otra pasta y tiene poco que ver con la vieja física, orientada por nacimiento y vocación hacia la metafísica. Al mismo tiempo, los que todavía reconocen el magisterio aristotélico a veces sacrifican y abandonan a sus adversarios precisamente la física, con lo que la metafísica queda huérfana de mediaciones para aprovechar la aportación cognitiva de la experiencia sensible. Precisamente ha sido la ruptura de los lazos antaño existente entre la física y la metafísica lo que más ha degradado la relevancia de la filosofía en el diálogo fe-ciencia. Simplemente la metafísica nada tenía que decir a la ciencia y nada quería escuchar de ella, a pesar de que Dios, hombre y mundo son en definitiva los asuntos sustantivos sobre los que la metafísica tiene que tratar y la ciencia no es sino la expresión canónica de lo que la experiencia nos dice del mundo y en una parte considerable también del hombre. Es evidente que la tenaz decisión de atenerse a lo empíricamente constatable cercena de raíz las posibilidades de decir algo relevante con respecto a Dios. Por otra parte, cuando uno se empecina en despreciar el valor de la experiencia a la hora de obtener un saber con altura especulativa, prácticamente renuncia a llegar muy lejos en el conocimiento del mundo y las dimensiones terrenas del hombre. Por consiguiente, para que la filosofía desempeñe un papel significativo en las relaciones entre ciencia y religión, es imperativo que permanezca fiel al paradigma de la unidad del saber, que fue mantenido por todos los grandes filósofos al menos desde Aristóteles hasta Leibniz. Después de Kant dicho paradigma ha sido puesto en cuestión, y ello explica la declinante posición de la filosofía en el contencioso que nos ocupa. De un tiempo acá han aumentado las voces que pretenden eliminar a la filosofía del diálogo ciencia-religión, diálogo paulatinamente orientado hacia la convivencia civilizada de dos instancias extrañas o muy alejadas una de otra.

Sostengo, en resumidas cuentas, que la incapacidad de la filosofía para potenciar el diálogo entre ciencia y religión manifiesta la decadencia de la propia filosofía. Pero además repercute negativamente en la teología, ten- 
tándola para que se ciña a ser hermenéutica de los textos sagrados, glosa del mundo interior del creyente o fenomenología de la experiencia religiosa. A mi juicio todas estas vertientes de la reflexión teológica resultan buenas y valiosas, pero son insuficientes, ya que la vocación irrenunciable del hombre es buscar a Dios y conocer su obra creadora con todos los dones que tiene a su disposición, y no sólo con una parte de ellos. Por otro lado, como ya apuntó Etienne Gilson, cuando se impide a una facultad cognitiva llegar de alguna manera a su término natural, que siempre es Dios, progresa torcidamente hacia su negación. La racionalidad atea es literalmente una razón dejada de la mano de Dios, de la que tendrán que responder no sólo los que la volvieron contra su propia raíz, sino también los que no se emplearon a fondo para que cumpliera sus legítimas expectativas (Gilson 1960).

Ya he dicho que en su origen y momentos de esplendor la tradición aristotélica patrocinaba la unidad del saber. Defendía que la física desembocaba naturalmente en la metafísica, a la que concebía en gran medida como teología filosófica. Resulta muy chocante cómo una parte de esta tradición llegó a desvincularse de sus señas de identidad. La vocación teológica de la metafísica es lo que la convierte en interlocutora privilegiada de la teología revelada, que a su vez actúa como portavoz autorizado de la religión. De no mediar la metafísica, el diálogo entre ciencia y religión se hace mucho más problemático, ya que los intervinientes tienden a encerrarse por un lado en una razón vuelta hacia la inmanencia y, por otro, en una fe privada de referentes empírico-racionales. Además, la metafísica pierde buena parte de su contenido teológico cuando se separa de la física, porque se engolfa en especulaciones abstractas y se distancia de la dimensión existencial de lo real. Debe recordarse que las cinco vías tomistas para llegar a la existencia de Dios parten de constataciones verificables en el ámbito de la física, y tanto la primera como la quinta lo hacen de un modo notorio y estable. La pregunta entonces obligada es ¿por qué motivo se abandonó explícita o implícitamente esta línea de investigación tan asentada y fructífera? No es el momento de perderse en complicadas consideraciones históricas, pero haré un par de comentarios elementales. 
Es sabido que Kant, en la dialéctica trascendental de la Crítica de la razón pura examina y condena las pretensiones teóricas de la cosmología filosófica y la teología natural. Dentro de la corriente neoescolástica algunos pensadores, cuyo exponente más destacado fue Joseph Maréchal, entraron en diálogo con la filosofía kantiana. Hay motivos para sospechar que se produjo a raíz de ello cierta kantianización de su aristotelismo, con consecuencias deplorables para el asunto que examinamos. No descarto que algo de eso haya ocurrido y tampoco pretendo minimizar su importancia. Pero las raíces del fenómeno son más antiguas y se remontan por lo menos hasta el comienzo de la Edad Moderna. Fue entonces cuando irrumpió la nueva racionalidad científica, que combinaba el empirismo aristotélico con el matematicismo platónico. La escolástica no atravesaba entonces su mejor momento, entre otras causas debido a la crisis nominalista. Sin embargo todavía protagonizaba la escena filosófica, y lo cierto es que no supo reconocer la importancia ni ubicar adecuadamente el nuevo estilo de indagar la verdad. Los actores decisivos de este proceso fueron los miembros de tres generaciones de la escuela jesuítica del Barroco, en la primera de las cuales destacaron Francisco de Toledo, Benito Pereira y Pedro de Fonseca; Gabriel Vázquez, Francisco Suárez, los Conimbricenses y Antonio Rubio, en la segunda; y Pedro Hurtado de Mendoza, Francisco de Oviedo y Rodrigo de Arriaga, en la tercera. Para lo que ahora interesa la figura más representativa es Sebastián Izquierdo, cuyo prestigio fue determinante tanto en el Colegio Imperial de Madrid como en el Colegio Romano. En 1659, esto es, 22 años después de que apareciera el Discurso del método de Descartes, publicó su Pharus Scientiarum, todo un ensayo enciclopédico que intentaba responder al desafío de la nueva racionalidad. Es muy posible encontrar aquí una última y especialmente desdichada secuela del conflicto que estalló entre Galileo y la orden jesuítica, porque en lugar de tomar como patrono de la nueva reorganización del saber al toscano, o a Kepler, o incluso a Descartes, se eligió a Francis Bacon y su chato empirismo, que era escasamente conciliable con cualquier ambición metafísica (Izquierdo 1659, vol.1). El resultado fue el que era de esperar: Izquierdo y con él buena parte de su escuela efectúa una bipartición del 
saber que enfrenta la física a la metafísica. Como resume José Luis Fuertes, especialista en este autor:

Todas las ciencias, según este supuesto, se pueden reducir o bien a la física o bien a la metafísica. La física fundará sus principios en la experiencia, ya que su objeto es el ente existente en acto, y la metafísica en el entendimiento humano, ya que su objeto es el ente, tanto imposible como posible, prescindiendo de la existencia (Fuertes Herreros 2012, 228).

Lo verdaderamente chocante es que en esta división la matemática queda adscrita a la metafísica, ¡mientras que la teología se encuadra dentro de la física! (Izquierdo 1659, vol.2) Pregunté a Fuertes por la justificación de tan insólito maridaje y subordinación. Lo refirió a la sentencia "la fe viene por el oír" (Romanos 10: 16). Si fuera así, también podría haberse puesto la teología bajo el patrocinio de la acústica o la fisiología del sistema auditivo. Se entiende que, a la larga, para el teólogo adscrito a esta orientación fuera más relevante el diálogo con la ciencia en particular que con la filosofía en general, y que tanto la matemática con la metafísica quedaran encerradas en un abstracto esencialismo que daba la espalda al actus essendi. Comparativamente era mucho más sana la filosofía racionalista de Descartes o Leibniz, pues ésta mantenía abierta la comunicación orgánica entre física, metafísica y matemática. A diferencia de muchos escolásticos tardíos, los racionalistas interpretaban la matemática como ciencia de las formas separadas en general, y no como ciencia de lo escuetamente cuantitativo. Haciéndolo así, la matemática aseguraba la conexión formal de la física con la metafísica. También posibilitaron que la física transmitiera tanto a la matemática como a la metafísica el impulso necesario para que ninguna de ellas olvidara el ser en acto. Esto explica el enorme auge de las pruebas teleológicas de la existencia de Dios en los siglos XVII y XVIII, que en sus mejores versiones estaban basadas en el descubrimiento de que las leyes de la naturaleza descansan en un esqueleto matemático extraordinariamente bello y poderoso, que en modo alguno puede ser fruto de la casualidad. Las discusiones en torno al principio de mínima acción constituyen un ejemplo entre muchos a este respecto (Arana 1994, 87-141). 
Una vez más es de lamentar que la escolástica moderna, arrastrada por la escuela jesuítica a una miope negación del matematicismo galileano, no aprovechara las posibilidades únicas que la ciencia moderna ofreció para efectuar una síntesis enriquecedora de Aristóteles con Platón y Arquímedes. Abandonada a sí misma, la metafísica racionalista moderna languideció, la teología finalista fue decayendo en planteamientos cada vez más ingenuos y empiristas (como muestra la trayectoria de la teología física inglesa en los siglos XVIII y XIX), y finalmente Kant pudo pronunciar su sentencia inapelable contra la pretensión de llegar a Dios por otra vía racional que no fuera el teísmo moral. Para colmo de males, una parte del aristotelismo neoescolástico cayó en la trampa del idealismo trascendental kantiano, con lo cual quedaron prácticamente arruinadas las perspectivas de llevar a cabo el diálogo fe-razón en un foro que no estuviera viciado por prejuicios y desconfianzas mutuas insuperables. Por esa vía lo mejor que se podía esperar es el ya comentado principio de los dos magisterios que no se superponen, cuyo más genuino representante dentro del campo de los creyentes es el físico e historiador de la ciencia Pierre Duhem (Jaki 1996).

No habría muchos motivos para sentirse optimista sobre la evolución de las relaciones entre fe y razón si sólo dependiésemos de los esfuerzos humanos, de nuestra voluntad y aciertos. Por fortuna no son esos los únicos factores que intervienen en la historia. Los enemigos de la religión han bailado danzas victoriosas sobre la tumba de la teología física, un torpe género apologético urdido por Newton y sus bienintencionados discípulos, y del cual constituye una prolongación contemporánea el creacionismo y la teoría del diseño inteligente. Pero la retórica antiteológica se equivoca cuando cree que en eso se resume todo lo que la razón es capaz de hacer para encontrarse con la fe. Con independencia de la actitud que haya habido tras la furia de los apologistas del ateísmo, lo cierto es que han prestado un servicio señalado a la religión, puesto que hace casi tanto por ella quien destruye malos argumentos como el que los construye buenos. Anthony Collins señalaba con cinismo que en Londres a nadie se le había ocurrido dudar de la existencia de Dios hasta que Bentley y otros virtuosos seguidores de Newton se les ocurrió intentar demostrarla (Collins 1713; Lechler 
1965, 222 ss ). A lo cual hay que replicar que los argumentos defectuosos ciertamente no validan lo que pretenden, pero tampoco consiguen lograr el efecto opuesto, salvo únicamente en opinión del que se deja llevar por las primeras impresiones. Jorge Luis Borges comenta a otro propósito, pero con cierto paralelismo:

Mientras un autor se limita a referir sucesos o a trazar los tenues desvíos de una conciencia, podemos suponerlo omnisciente, podemos confundirlo con el universo o con Dios; en cuanto se rebaja a razonar, lo sabemos falible (Borges 1989, 76).

Razonar, en efecto, no es una operación que podamos atribuir a Dios: implica discurso, temporalidad, elección de premisas. Todo ejercicio de la razón implica en último término riesgo de fracaso y también esperanza de éxito. Esta facultad está por naturaleza unida a la epistemología del riesgo y por tanto no puede erigirse en tribunal supremo de la verdad. Saber que nuestros teoremas pueden contener falacias no debe hacernos renegar de la razón, tan sólo enseña a desconfiar de nosotros mismos y ejercer sin descanso la autocrítica.

En estas condiciones, gracias a Collins y a un largo etcétera que en nuestros días contemplaría autores como Dawkins, Onfray y tantos otros, hemos conseguido obtener en la actualidad una panorámica bastante completa de las pseudodemostraciones de la existencia y naturaleza de Dios. Hay que agradecérselo, porque de esta suerte el terreno ha quedado despejado para que prosperen en él las buenas pruebas, pruebas que nunca han faltado, ni entonces ni ahora. Aludiré a alguna de las que había entonces y también a una o dos de las que se barajan ahora.

Es muy curioso y llamativo constatar que los críticos más obstinados de la teología natural, David Hume e Immanuel Kant, reconocieron ambos que la quinta vía de Santo Tomás en realidad constituía un argumento teórico bastante convincente. Lo cierto es que era y sigue siendo perfectamente válido si lo valoramos como es debido, esto es, desde la epistemología del riesgo y no desde una aporética epistemología de certezas apodícticas. La quinta vía se había transformado en el siglo XVIII en una diversidad de 
vías, en parte paralelas y en parte entremezcladas, a las que los autores solían referirse como "argumentos teleológicos" de la existencia de Dios. Habían proliferado enormemente bajo el impulso de la naciente ciencia natural, de modo que casi constituían una legión. El profesor Alejandro Llano suele contar un chiste en que un enojado obispo pregunta al responsable de la parroquia que viene a visitar por qué no han sonado las campañas para saludar su llegada. "Por nueve causas, su Ilustrísima; la primera: porque la Iglesia no tiene campanas...”. El prelado corta en seco y replica: "Si es así, me sobran las otras ocho...”. La historieta se podría aplicar a la inversa en este caso: si en aquella época se barajaban tantos argumentos teleológicos, quizá se debía a que ninguno de ellos resultaba plenamente convincente. Puede que fuera así, pero los jueces saben bien que cuando no hay pruebas irrefutables, la acumulación de indicios tiene algo que aportar. El caso es que hasta el escéptico Hume llegó a vacilar y pensó seriamente en dar su brazo a torcer:

Un propósito, una intención, un designio se imponen por todas partes al más negligente, al más estúpido pensador; y nadie puede estar tan obcecado en absurdos sistemas como para negarse continuamente a admitirlo. [...] ¿A qué grado de pertinaz obstinación tiene que haber llegado un filósofo de nuestro tiempo para poder dudar ahora de la existencia de una inteligencia suprema? (Rodríguez 1998, 30-31).

Tras este ataque de sinceridad se esforzó al máximo con el fin de rebajar sus propias expectativas teóricas, de manera que la potencia previsora y conformadora que transparenta el orden cósmico quedara degradada a un descafeinado principio casi anónimo:

La causa o causas del orden del universo presentan probablemente alguna remota analogía con la inteligencia humana. [...] Si esa proposición no es susceptible de extensión, de variación o explicación más particular; si no proporciona ninguna inferencia que afecte a la vida humana o que pueda ser la fuente de alguna acción o alguna abstención; y si la analogía, imperfecta como es, no puede extenderse más allá de la inteligencia humana... Si tal es realmente el caso, ¿qué puede hacer el hombre más inquisitivo, más contemplativo y más 
religioso sino prestar su asentimiento franco, filosófico a la proposición tantas veces como se presente...? (Rodríguez 1998, 32)

Desde mi punto de vista, este es un claro ejemplo de aplicación asimétrica del criterio de rigor en una búsqueda racional. Es evidente que ninguna investigación relativa a la existencia de entidades externas al propio sujeto investigador puede llegar a evidencias comparables con las de un teorema matemático. El filósofo no es capaz de ofrecer ese tipo de certeza y el científico tampoco. En el siglo XVII los creadores de la nueva ciencia descubrieron que podían prescindir de certezas así y sin embargo obtener conocimientos valiosos, aunque basados en conjeturas y sólo parcialmente validados. Así desarrollaron una epistemología del riesgo, iniciando lo que desde muchos puntos de vista ha de ser considerada la edad de oro de la investigación. Los filósofos que vivieron inmediatamente después aceptaron, como Hume, que había que aflojar las exigencias para acreditar una tesis de la física, pero no rebajaron ni un ápice las que se referían a la metafísica, incluso cuando no era fácil apreciar los límites que separaban una investigación física de sus prolongaciones metafísicas. Todo el mundo aceptará que la física no permite precisar la naturaleza y alcance del Ser infinito y necesario (entre paréntesis añadiré que tampoco ningún otro producto de la inteligencia humana). Sin embargo, puede perfectamente detectar una entidad que desborda absolutamente los límites de cualquier potencia cósmica concebible. Dar el paso de identificarla con Dios implica ciertamente un riesgo, pero en determinadas condiciones supone un riesgo perfectamente razonable y asumible, semejante al de un investigador que identifica la causa de una enfermedad con la presencia de un patógeno ciertamente presente y capaz de provocarla, aunque no pueda descartar con seguridad superlativa todas y cada una de las mil y una retorcidas hipótesis alternativas imaginables.

Se cuenta que el científico responsable de una confirmación empírica importante del modelo cosmológico de la gran explosión estaba entusiasmado con las connotaciones teológicas del hallazgo. “iAlto ahí! - se le dijo- Nadie ha demostrado aún que el big bang sea el comienzo absoluto 
del universo..." "Estoy de acuerdo - repuso-. Pero, mientras no aparezca ninguna alternativa mejor, podremos apañarnos bien con esta”. Algunos considerarán su respuesta poco seria y típica del pragmatismo de los hombres de ciencia, pero bien considerada no es otra cosa que un ejercicio responsable de la epistemología del riesgo: si para aceptar como buena una teoría científica no se exige más que un grado $x$ de plausibilidad, ¿por qué ha de pedirse otro significativamente mayor para sacar consecuencias acerca de la presencia de Dios como autor del universo? Ninguna evidencia procedente de la física despejará todas las incógnitas que figuran en la indagación teológica, pero puede arrojar bastante luz a la hora de desechar la idea de que el azar, la materia, o una deidad inmanente como la que promueve el panteísmo sean respuestas satisfactorias a la pregunta por el origen. Conviene tener presente que la pregunta por el origen radical de todas las cosas una pregunta urgente, de máxima urgencia para cada uno de nosotros los mortales, como recuerda el filósofo Antony Flew:

...mi persistente interés en la religión fue siempre sólo prudencial, moral, o simplemente curioso. Digo "prudencial" porque, si hay un Dios o dioses que se implican en los asuntos humanos, sería descabelladamente insensato no mantenerse en el lado correcto, cuando de ellos se trata (Flew 2012).

Nadie optaría por la epistemología del riesgo si pudiera resolver las cuestiones que le afectan con una epistemología de la certeza. Pero lo que no tiene pies ni cabeza es aplicar unas veces sí y otras no la epistemología del riesgo cuando nos vemos en la imposibilidad de usar sistemáticamente la de la certeza. Ya hemos visto que la ciencia no es otra cosa que un puñado de verdades arriesgadas (con riesgos medidos, eso está claro, pero riesgos al fin y al cabo). ¿Por qué negar a la filosofía el derecho de hacer otro tanto y arriesgarse con las verdades que más importan?

Si alguien con anterioridad ha escuchado mis clases o leído mis escritos, adivinará sin dificultad que ha llegado el momento de entregarme a uno de mis pasatiempos favoritos, consistente en meterme un poco con Kant. En efecto: el filósofo alemán cometió el error imperdonable de pensar que las verdades de la ciencia eran absolutamente seguras, lo que le llevó 
a perseguir en filosofía el mismo espejismo de garantía epistémica. Sólo en este segundo ámbito se dio cuenta del carácter ilusorio del empeño, lo que le hizo desistir de una porción de objetivos teóricos, muy en particular los que tienen que ver con la teología natural. Lo más desgraciado del asunto es que su fracaso a la hora de intentar llevar la metafísica por la senda de la evidencia, no le hizo recapacitar y reconocer que tampoco la ciencia iba por ella.

Hay en la Crítica de la razón pura un pasaje crucial donde Kant advierte que la fiabilidad del argumento teleológico es más que razonable. En ese momento está a punto de dar el paso decisivo hacia la epistemología del riesgo:

...diría demasiado poco si calificara de opinión mi tener por verdad [la existencia de un sabio autor del mundo]. Incluso en este aspecto teórico puede decirse, más bien, que creo firmemente en Dios. En términos estrictos, no es entonces práctica esa creencia, sino que hay que calificarla como una creencia doctrinal a la que la teología de la naturaleza tiene que dar lugar siempre y de modo necesario (Kant 1978, A827, B855).

Pero, obsesionado con las seguridades que cree haber descubierto en la mecánica newtoniana, da un paso hacia atrás y renuncia a dar por buena la consiguiente apuesta teórica. Este paso atrás ha costado a la filosofía doscientos años de impotencia respecto al logro de sus propios fines y además la ha inhabilitado para mediar en el diálogo ciencia-religión. En amplios sectores de la filosofía continental europea todavía se vive la misma angustiosa y estéril búsqueda de lo apodíctico, pero círculos escogidos del pensamiento anglosajón parecen haber salido del trance y superado el síndrome. La teología natural prospera tanto en Inglaterra como en Estados Unidos, y no tanto o no sólo como género apologético, sino como disciplina académica en la que coexisten las más diversas corrientes y posiciones, tanto teístas como ateas. Se discuten cada vez menos cuestiones previas y de principio, como por ejemplo, si tiene sentido plantear la pregunta por Dios, o de si antes de abordarla hay que coleccionar suficientes pruebas de convicción para que la respuesta tenga una credibilidad equiparable a la afirmación de 
que la suma de los tres ángulos de un triángulo euclidiano es igual a dos rectos. El centro del interés se ha ido desplazando al análisis comparativo de los argumentos en pro y en contra, al refinamiento de los conceptos, a la evaluación de las consecuencias últimas de asumir una posición u otra.

Los debates dentro de la teología natural contemporánea son vivos y pródigos en novedades, como cuando en 2004 el prestigioso mantenedor de opciones teóricas ateas Antony Flew anunció que, tras cuarenta años de indagaciones, cambiaba de bando y asumía posiciones teístas. En cualquier caso, las anécdotas importan menos que la existencia de una pléyade de autores que están en diálogo permanente abierto con los científicos -de cuyas filas provienen en bastantes casos-y defienden con razones renovadas tesis que en muchos casos tienen una larga historia tras de sí. Autores como Michael Heller, William Lane Craig, Richard Swinburne, William Stoeger, David Conway, John Polkinghorne y muchos más certifican que no se trata de una cosecha efímera. Pero tampoco quiero ampararme en argumentos de autoridad. Más aún que los autores abundan los argumentos, precisamente en un momento histórico en que el naturalismo está promoviendo una ofensiva en toda regla contra la cosmovisión religiosa, apoyándose sobre todo en la biología evolutiva y las neurociencias. Es muy curioso, pero diríase que mientras unas ciencias parecen proclives a interpretaciones ateas y materialistas, otras tienden a favorecer la imagen de un universo que es producto de una Voluntad sabia y poderosa. El fenómeno tiene un lejano parentesco con lo que ocurrió a nivel social en el siglo XVIII: las capas sociales altas empezaron a descristianizarse, mientras las populares y rurales elevaron su tono moral y se hicieron más profundamente cristianas. Ahora no se trata de las personas, sino de los saberes. Pero la disparidad es chocante: tanto en cosmología como en física de partículas hay que esforzarse mucho para negar o disimular los indicios de creación y diseño. En cambio los que se dedican a biología molecular o investigan la fisiología del sistema nervioso tienden a proclamar que esperan explicar tanto la vida como el hombre sin recurrir a ningún principio de tipo espiritual. Lo insólito de la situación es que tradicionalmente la historia natural era una cantera de argumentos piadosos, mientras que 
en la física se intentaba buscar un saber último basado en la inmanencia. Muchos portavoces de la neurociencia y biología contemporáneas reniegan de dualismos o vitalismos y reclaman el patrocinio de la física, ciencia más madura que rápidamente está limando las aristas que anteriormente chocaron con concepciones religiosas o humanistas. La situación recuerda al viejo adagio según el cual un poco de ciencia aleja de Dios, mientras que mayor abundancia de conocimientos y más aquilatado rigor aproximan de nuevo a Él. Yo creo francamente que así es. Ya no se trata tan sólo, por consiguiente, del diálogo entre la ciencia y la religión: es el diálogo entre las diferentes ramas de la ciencia el que debe ser potenciado, para poner en claro lo que dentro de ellas puede haber de precipitadas extrapolaciones formuladas a partir de pesquisas todavía incompletas, y lo que hay de legítima aspiración a un saber más amplio, más profundo, más verdadero. Ese es el trabajo de los científicos y de los hombres de fe. Pero también, cómo no, de los teólogos y de los que nos dedicamos a la filosofía. Hay una cosecha abundante que recoger. No dejemos que se pudra en el campo o se enmohezca en los almiares.

\section{Referencias}

Arana, Juan. 1994. La mecánica y el espíritu. Leonhard Euler y los orígenes del dualismo contemporáneo. Madrid: Editorial Complutense.

Benedicto XVI. 2011. Carta apostólica “Porta fidei”. Roma: LEV.

Borges, Jorge Luis. 1989. “Otras Inquisiciones.” In Obras completas, vol. 2. Barcelona: Emecé

Collins, Anthony. 1713. Discurso sobre el librepensamiento. Holanda.

Flew, Antony. 2012. Dios existe. Madrid: Trotta.

Fuertes Herreros, José Luis. 2012. El discurso de los saberes en la Europa del Renacimiento y del Barroco. Salamanca: Ediciones Universidad de Salamanca.

Gilson, Etienne. 1960. La unidad de la experiencia filosófica. Madrid: Rialp.

Gould, Stephen Jay. 2000. Ciencia versus religión. Un falso conflicto. Barcelona: Crítica. Izquierdo, S. 1659. Pharus Scientiarum ubi quidquid ad cognitionem humanam acquisibilem pertinet... verae Encyclopaediae Orbis facile a cunctis circunvolvendus, eximio scientiarum omnium emolumento, manet expositus, 2 vols. Lugduni: sump. Claudii Bourgeat, et Mich. Lietard. 
Jaki, S. 1996. La ciencia y la fe. Pierre Duhem. Madrid: Encuentro.

Juan Pablo II. 1998. Encíclica “Fides et ratio". Roma: LEV.

Kant, Immanuel. 1978. Crítica de la razón pura. Madrid: Alfaguara.

Lechler, Gotthard Victor. 1965. Geschichte des englischen Deismus. Hildesheim: Olms.

Rodríguez, José Luis, trans. 1998. Hume. Dios. Pamplona: Cuadernos de Anuario Filosófico. 